\title{
Extracorporeal membrane oxygenation for cardiac arrest during moyamoya cerebral revascularization surgery: case report
}

\author{
Omar Choudhri, MD, ${ }^{1}$ Aatman Shah, BS, ${ }^{1}$ Jennifer Basarab-Tung, MD, ${ }^{2}$ \\ Richard A. Jaffe, MD, PhD, ${ }^{1,2}$ and Gary K. Steinberg, MD, PhD' \\ 1Department of Neurosurgery and Stanford Stroke Center, and 2Department of Anesthesiology, Stanford University School of \\ Medicine, Stanford California
}

\begin{abstract}
The authors describe the case of a 51-year-old man with bilateral moyamoya disease and prior strokes who developed an asystolic cardiac arrest while undergoing revascularization surgery under mild hypothermia. The patient was successfully treated with venoarterial (VA) extracorporeal membrane oxygenation (ECMO) after manual cardiopulmonary resuscitation (CPR) was unsuccessful for 45 minutes. ECMO is a cardiopulmonary support system that is indicated for respiratory failure in pediatric and adult patients. It is increasingly being used as an extension to mechanical CPR for patients who have suffered cardiac arrest if the underlying cause of cardiac arrest is thought to be reversible. Identifying which patients should be placed on emergency ECMO after cardiac arrest is controversial given its high morbidity and mortality. ECMO in neurosurgical settings has associated risks of intracranial hemorrhage and neurological compromise, while resource utilization is paramount given the high costs of this treatment. This paper is significant because it describes the use of ECMO in an unindicated setting. Limited data are available for ECMO usage after cardiac arrest with baseline cerebral ischemia. Furthermore, this paper raises important considerations for extracorporeal CPR use in a patient who had recently undergone craniotomy. The patient in this report remained on ECMO for 48 hours, after which he was successfully weaned. He developed a pericardial effusion and compartment syndrome from the ECMO but made a complete neurological recovery. Use of ECMO emergently in an appropriately chosen neurosurgical patient is safe, even in the setting of baseline cerebral ischemia and recent craniotomy.
\end{abstract}

http://thejns.org/doi/abs/10.3171/2014.11.JNS141054

KEY WORDS ECMO; hypothermia; cerebral revascularization; cardiac arrest; vascular disorders

$\mathrm{C}$ ARDIOPULMONARY bypass using the heart-lung machine was initiated in 1937 by Gibbons and subsequently has been used for open cardiac surgery since $1954 .{ }^{15}$ However, given the limitations of membrane oxygenation, it could not be used for long durations. ${ }^{41}$ This gave way to the development of extracorporeal membrane oxygenation (ECMO) in 1972 by Hill et al. ${ }^{18,31}$ ECMO is a last-resort intensive care technique indicated during cardiopulmonary failure due to potentially reversible causes. ECMO provides circulatory support by assuming the role of the heart and lungs to maintain blood flow and oxygenation to the vital organs, including the brain. ${ }^{14}$ Most data on the success of ECMO come from its primary indica- tion for respiratory failure in newborns. Four prospective randomized controlled trials in newborns and one in adults have shown a significant survival advantage with ECMO for severe respiratory distress..$^{11,29}$ The data and indications for ECMO in the setting of cardiac failure are still evolving. Conventional extracorporeal circuits are routinely used in elective cardiac surgery where the right atrium and aorta are directly cannulated to allow unobstructed flow. ${ }^{15}$ Although ECMO is derived from cardiopulmonary bypass, differences between them include minimal heparin use, peripheral cannulation, lack of a cardiotomy reservoir, and no autotransfusion. ${ }^{6}$

Since these early developments, ECMO has transi-

ABBREVIATIONS $\mathrm{CPR}=$ cardiopulmonary resuscitation; $\mathrm{EC}-\mathrm{IC}=$ extracranial-to-intracranial; $\mathrm{ECMO}=$ extracorporeal membrane oxygenation; ECPR $=$ extracorporeal $\mathrm{CPR} ; \mathrm{MMD}=$ moyamoya disease $; \mathrm{VA}=$ venoarterial; $\mathrm{VV}=$ veno-venous .

SUBMITTED May 13, 2014. ACCEPTED November 25, 2014.

INCLUDE WHEN CITING Published online May 22, 2015; DOI: 10.3171/2014.11.JNS141054.

DISCLOSURE Dr. Steinberg serves on the Neuroscience Advisory Board for Medtronic, Inc. Funding was provided by Josef Huber Family Moyamoya Fund, Stanley and Alexis Shin, Reddy Lee Moyamoya Fund, William Randolph Hearst Foundation, Bernard and Ronni Lacroute, and Russell and Elizabeth Siegelman (G.K.S.). 
tioned to use in both adults and children for respiratory and cardiac failure. The success of ECMO for cardiac failure varies, with survival rates between $23 \%$ and $71 \% .{ }^{36}$ The best survival rates, seen in patients exhibiting cardiac failure from myocarditis, are as high as $71 \% .^{40}$ An extension of ECMO, known as extracorporeal cardiopulmonary resuscitation (ECPR), is emergency ECMO for cardiac arrest when resuscitation after manual CPR has failed. ${ }^{21,40}$ ECPR provides an interval during which the underlying process leading to cardiac arrest can recover ${ }^{39}$ ECMO in select patients who have suffered cardiac arrest may improve survival, but there are no clearly defined guidelines and data are controversial. ${ }^{33}$ The upper time limit of manual CPR after which ECPR will no longer result in good neurological outcomes is not known. Chen et al. noted a significant survival advantage of ECPR in patients with refractory arrest longer than 10 minutes; they noted an approximately $20 \%$ increase in survival and improved neurological outcome in the ECPR group compared with the conventional CPR group. Initial rhythm can determine outcomes in cardiac arrest, with asystole or pulseless electrical activity having a worse prognosis than ventricular fibrillation or ventricular tachycardia.? A randomized trial of ECPR would be difficult given the emergency nature of in-hospital cardiac arrest. ${ }^{33}$

Neurological injury after ECMO is a significant concern that was first raised in neonates who developed complications, including ischemic and hemorrhagic strokes secondary to heparinization and steal phenomenon. ECMO carries a high risk of brain injury, with studies showing severe neurological complications in roughly $40 \%-50 \%$ of adults. ${ }^{25,30}$ The risk of intracranial hemorrhage after ECMO in children is $7 \%$, based on contemporary data., ${ }^{2,17}$ Mateen et al. noted neurological complications, including subarachnoid hemorrhage, ischemic infarcts, and hypoxic ischemic encephalopathy, in 42 of 87 adult patients who received ECMO ${ }^{25}$ ECMO for cardiac arrest in the setting of baseline ischemia places the patients at higher risk for strokes.

We present an unusual case of a patient with moyamoya disease (MMD) who developed cardiac arrest during cerebral revascularization surgery that failed to respond to 45 minutes of CPR. A decision was made to use ECPR, and the patient made a complete recovery without any neurological sequelae. This reported case is particularly salient because ECMO was used in a nonindicated setting on a patient with a baseline of cerebral ischemia and recent craniotomy who was pulseless and asystolic for 45 minutes before the start of ECMO and who subsequently recovered without neurological complications.

\section{Case Report}

A 51-year-old man was admitted to our hospital for elective extracranial-to-intracranial (EC-IC) bypass surgery to treat his symptomatic MMD. The patient first presented 4 years earlier with generalized weakness. An initial examination revealed subclavian artery stenosis, and the patient's symptoms progressively worsened. He subsequently underwent stenting of his right subclavian artery, which provided a reprieve from notable symptoms.

The following year he developed right-sided weakness and numbness. Angiograms disclosed occlusion of the left cervical internal carotid artery and occlusion of the right supraclinoid internal carotid artery with extensive moyamoya vessels bilaterally (Fig. 1A and B). An MR image demonstrated an old left posterior cerebral infarct as well as ischemic lesions in the bilateral white matter watershed territory (Fig. 1C). The patient underwent a left EC-IC revascularization procedure, during which he was extremely hypotensive, requiring boluses of vasopressin and epinephrine as well as a vasopressin infusion. This refractory hypotension was attributed to his concurrent treatment with an angiotensin receptor blocker and aliskiren, a direct renin inhibitor. His postoperative course was uncomplicated. Two weeks later, after confirming that his electrocardiography findings were unchanged from baseline and that he had abstained from his antihypertensive drugs for 24 hours, he underwent a planned right-sided EC-IC bypass.

During the second bypass procedure, the patient's core body temperature was cooled to $33^{\circ} \mathrm{C}$ using a cooling blanket. After harvesting the superficial temporal artery and performing the craniotomy with removal of the bone flap (before the dura was opened), the patient suffered a sudden asystolic cardiac arrest of unknown etiology. The intracranial procedure was aborted and CPR was immediately commenced. Advanced cardiac life support was initiated and continued for 45 minutes but the patient remained pulseless. However, the patient's pupils continued to be reactive, the arterial line showed a mean arterial pressure of approximately $50 \mathrm{~mm} \mathrm{Hg}$ with chest compressions, and at times the patient was noted to move his arms during this effective CPR despite an absence of intrinsic cardiac activity. In this situation, the interventional cardiology service was asked to insert femoral bypass cannulae for ECMO. The patient remained under anesthesia, and his core temperature was kept at $33^{\circ} \mathrm{C}$ throughout the resuscitation procedure. Right femoral arterial and venous catheters were placed for ECMO to continue perfusing his organs, including the brain. An emergency percutaneous angiogram failed to show any abnormalities in the coronary circulation and vasculature. The patient was kept on ECMO for the next 48 hours, during which time his cardiac function slowly returned. The patient's recovery was complicated by a pericardial tamponade, which was drained using a pericardial window, as well as compartment syndrome in his right lower extremity, which required a 4-compartment fasciotomy. The patient was followed up with serial CT scanning, which showed no change in the size of his small postoperative epidural hematoma (Fig. 1D). The patient subsequently made a complete neurological recovery with no deficits. He was later discharged home with no notable neurological sequelae and remained neurologically intact at 1-year follow-up. Although it was postulated that vasoplegia from antihypertensive treatment, coronary vasospasm, and/or exacerbation of a preexisting conduction system defect may have contributed to his intraoperative cardiac arrest, an etiology was never ultimately determined.

\section{Discussion}

ECMO is routinely accomplished with a veno-venous 

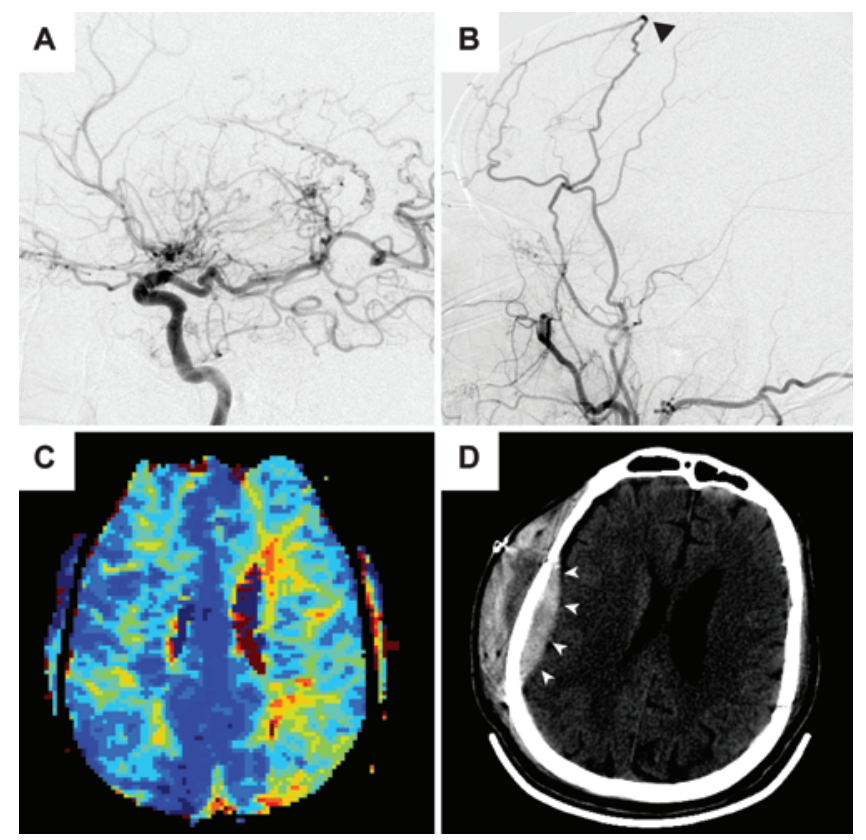

FIG. 1. Pre- and postoperative images. A: Lateral-projection preoperative angiogram of the right internal carotid artery demonstrating an occluded supraclinoid segment with multiple moyamoya vessels. B: Lateral-projection preoperative angiogram of the right external carotid artery with some transdural leptomeningeal collaterals from the middle meningeal artery (arrowhead). C: Preoperative MRI perfusion image map with perfusion delay in both cerebral hemispheres (left greater than right). D: Noncontrast axial head CT image demonstrating a small right epidural hematoma (arrowheads) at the site of craniotomy for bypass surgery, which was aborted.

(VV) circuit or a venoarterial (VA) circuit. ${ }^{40}$ The choice of technique depends on whether the primary problem lies with oxygenation or circulation. Essentially, VV-ECMO replaces the function of the lungs by returning oxygenated blood to the venous system, and a functioning heart is required to deliver the oxygenated blood to vital organs. VAECMO replaces the functions of both heart and lungs by returning oxygenated blood to the arterial system without requiring intrinsic cardiac function (Fig. 2). VV-ECMO is used for severe but reversible respiratory failure, while VA-ECMO is used for severe cardiac or cardiopulmonary failure. ${ }^{36}$

Cerebral injury from ECMO has been extensively studied in infants and could be the result of prolonged systemic heparinization, ligation of a carotid artery and jugular vein, alterations in pulsatile flow, especially in VA-ECMO, and potential exposure to microthrombi and plasticizers from the ECMO circuit. ${ }^{34}$ These injuries may be seen in adult ECMO with an increased risk for cerebral injury in the presence of pre-ECMO ischemia..$^{25}$ Early animal studies noted decreased cerebral oxygenation, altered cerebral autoregulation, and increased lactate despite normotension with extracorporeal life support..$^{20,35}$ Barrett et al. found acute neurological injury in $22 \%$ of pediatric patients undergoing ECPR from their retrospective review of the Extracorporeal Life Support Organization registry. They noted that lack of metabolic acidosis and underlying cardiac disease decreased the odds of neurological
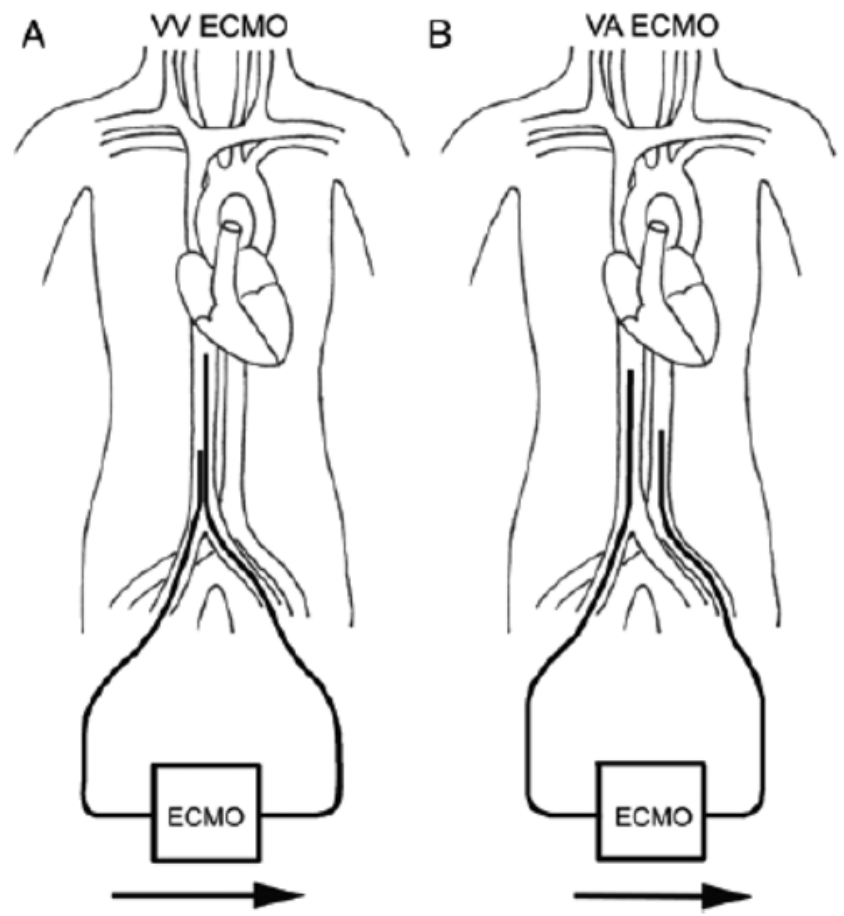

FIG. 2. Setup of an ECMO circuit. A: VV-ECMO circuit with venous access into the bilateral femoral veins. B: VA-ECMO circuit with access into the right femoral vein and left femoral artery respectively. Reprinted with permission from Tsuneyoshi and Rao: The role of extracorporeal membrane oxygenation (ECMO) therapy in acute heart failure. Int Anesthesiol Clin 50:114-122, 2012, Wolters Kluwer Lippincott Williams \& Wilkins.

injury. Performing ECPR in a monitored unit resulted in improved outcomes in children with cardiac disease. ${ }^{2}$ This was highlighted in our patient in whom ECPR was performed in the operating room with a trained cardiac response team, neuroanesthesia, and effective CPR before and during ECMO cannulation, all of which may have helped to minimize neurological injury in our patient.

ECMO or cardiopulmonary bypass with hypothermic circulatory arrest has been used in the treatment of giant intracranial aneurysms, but this therapy fell out of favor due to complications associated with coagulopathy and hemorrhage. ${ }^{1}$ There are few reports of the use of ECMO in elective neurosurgery. ${ }^{19}$ Chen et al. shared their experience with heparin-bonded ECMO for the treatment of complex intracranial aneurysms and established safety with use of low-dose heparin without the need for circulatory arrest. ${ }^{6}$ Yen et al. used a heparin-bonded ECMO circuit for a patient after a decompressive craniectomy and avoided the need for systemic heparin. ${ }^{42} \mathrm{~A}$ recent report by Bruzek et al. demonstrated a similar lifesaving use of ECMO and systemic heparin in a patient with acute respiratory distress syndrome following a trauma craniectomy. ${ }^{3}$ Our case is the first report of the use of ECMO in an adult with MMD who was successfully resuscitated without any neurological injury. Furthermore, it highlights that ECPR may be indicated in a patient with potentially reversible cardiopulmonary arrest and baseline cerebral ischemia.

Chauhan et al. described the successful use of ECMO in a patient with a thoracic epidural abscess who was un- 
able to tolerate prone positioning for a laminectomy and decompression procedure due to cardiopulmonary collapse. The procedure was performed successfully after employing ECMO for hemodynamic stability while in the prone position. ${ }^{5}$ ECMO has been used successfully in a newborn who required respiratory support due to a congenital diaphragmatic hernia. Ligation of the right common carotid artery for ECMO led to MMD with the formation of external collaterals to the right hemisphere without cerebral ischemia, and no neurological injury in the left hemisphere. ${ }^{23}$ Friesenecker et al. performed a decompressive craniectomy and evacuation of an intracerebral hemorrhage under ECMO in a young polytrauma patient with adult respiratory distress syndrome after thoracic trauma. ${ }^{13}$ Hwang et al. safely used ECMO in a patient with neurogenic pulmonary edema who underwent successful clipping for a ruptured anterior communicating artery aneurysm. ${ }^{19} \mathrm{~A}$ major concern with ECMO therapy is the increased risk of intracranial hemorrhage from anticoagulation, especially in the setting of a craniotomy. ${ }^{26,27}$ Our report and these other cases, however, demonstrate that ECMO can be instituted in a craniotomy patient after cardiopulmonary collapse without significant intracranial bleeding or neurological sequelae. ${ }^{42}$

Mild hypothermia has been shown to improve the neurological outcome in patients when administered after the global cerebral ischemic event following cardiac arrest from ventricular fibrillation ${ }^{3,38}$ or perinatal hypoxicischemic injury. ${ }^{16,32}$ Therapeutic mild hypothermia is now considered a standard of care and is recommended as a guideline for patients with cardiac arrest. ${ }^{28}$ Therapeutic hypothermia can also improve survival in patients with cerebral ischemic damage before restoration of circulation. ${ }^{24}$ The benefit of mild hypothermia for neuroprotection in vascular neurosurgical cases is controversial, despite encouraging animal data. ${ }^{8,43}$ At our center we use mild hypothermia for all cerebral revascularization surgeries and, in addition to effective CPR, this may have contributed to reducing neurological damage during ECPR, especially since the patient was hypothermic $\left(33^{\circ} \mathrm{C}\right)$ before he suffered a cardiac arrest. Hypothermia via an intravascular cooling system can be instituted as part of the ECMO setup as it has its own temperature control system. Hypothermia can cause temporary dysfunction of the platelet and coagulation cascade, decreasing the heparin requirement for ECMO, and may help prevent thrombotic complications. ${ }^{6}$

Given the lack of guidelines about when to exclude patients from ECPR, each patient should be assessed with regard to neurological function and the quality of CPR provided. Chen et al. prospectively compared ECPR with conventional CPR among patients with in-hospital cardiac arrest requiring CPR for longer than 10 minutes. In this matched study they noted that ECPR had a $20 \%$ increase in survival rate and better neurological outcome. ${ }^{7}$ Some authors have argued that contraindications to ECPR include cardiac arrest longer than 30 minutes, which may not be appropriate in every case, as illustrated by our patient. ${ }^{37}$ A registry of patients receiving ECPR would help define parameters, such as CPR duration and oxygenation, that could guide the use of this therapy. ${ }^{21}$ Each patient should thus be considered for ECMO, but it is important to establish reversibility of the underlying cause before instituting it. Possible contraindications are uncontrolled bleeding, irreversible neurological or end-organ damage, and patients with end-stage cardiac disease or inaccessible vessels for cannulation. ${ }^{40}$ American Heart Association guidelines state that any patient with refractory CPR and potentially "reversible causes of cardiac arrest" is a candidate for ECMO. However, in a practical setting for neurosurgeons, favorable factors for ECMO after cardiac arrest include baseline minimal cardiac disease, witnessed cardiac event, effective CPR, and favorable arterial blood gases in the presence of active patient monitoring. ${ }^{4}$

Intraoperative neuromonitoring with electroencephalography, somatosensory evoked potentials, and motor evoked potentials was continued during cardiopulmonary resuscitation, but movement artifact from the CPR contaminated the recording. We therefore could not use the data to accurately assess the patient's neurological status. Intraoperative neuromonitoring during bypass procedures can sometimes be a helpful adjunct in patients undergoing bypass procedures, especially large-caliber EC-IC bypasses. ${ }^{10}$

Weaning from ECMO in patients receiving ECPR occurs after the resolution of myocardial stunning, which could take up to 1 week. The patient's cardiac ejection fraction is closely followed with echocardiography, and left ventricular ejection fraction greater than $30 \%$ appears to increase the likelihood of successful weaning. 9,12 The patients who are at risk for ECMO-related complications during this time need to be appropriately followed and treated. This was observed in our patient, who developed a pericardial effusion and a compartment syndrome while on ECMO. Given the risk of intracranial hemorrhage, patients should be monitored with serial CT scans, as was the case with our patient. ${ }^{22}$ For neonates, fontanelles should be assessed and serial head ultrasounds can be helpful to diagnose and follow an intracranial hemorrhage..$^{17}$

\section{Conclusions}

ECMO is a well-accepted therapy for respiratory failure and cardiac collapse in newborns and other patients with cardiac failure. Limited data are available for ECMO after cardiac arrest in a neurosurgical patient with baseline cerebral ischemia. This case illustrates the safe and successful use of ECMO after failed CPR in an acute neurosurgical setting. Furthermore, it raises important considerations for ECPR use in a patient with recent craniotomy. From a resource utilization standpoint, it should be noted that ECMO carries high monetary and personnel-related costs, and a reasonable assessment of a patient's chance of neurological recovery should be made before ECMO is initiated.

\section{Acknowledgments}

We thank Cindy H. Samos for help with preparation of the manuscript and Elizabeth $\mathrm{H}$. Hoyte for help with preparation of the images.

\section{References}

1. Aebert H, Brawanski A, Philipp A, Behr R, Ullrich OW, Keyl C, et al: Deep hypothermia and circulatory arrest for 
surgery of complex intracranial aneurysms. Eur J Cardiothorac Surg 13:223-229, 1998

2. Barrett CS, Bratton SL, Salvin JW, Laussen PC, Rycus PT, Thiagarajan RR: Neurological injury after extracorporeal membrane oxygenation use to aid pediatric cardiopulmonary resuscitation. Pediatr Crit Care Med 10:445-451, 2009

3. Bruzek AK, Vega RA, Mathern BE: Extracorporeal membrane oxygenation support as a life-saving measure for acute respiratory distress syndrome after craniectomy. J Neurosurg Anesthesiol 26:259-260, 2014

4. Chai PJ, Jacobs JP, Dalton HJ, Costello JM, Cooper DS, Kirsch R, et al: Extracorporeal cardiopulmonary resuscitation for post-operative cardiac arrest: indications, techniques, controversies, and early results - what is known (and unknown). Cardiol Young 21 (Suppl 2):109-117, 2011

5. Chauhan A, Moraca RJ, Altman DT: Use of extracorporeal membrane oxygenation support during an emergent decompression of a thoracic epidural abscess. Spine (Phila Pa 1976) 38:E1048-E1050, 2013

6. Chen YS, Ko WJ, Lin FY, Huang SC, Wang SS, Tu YK: New application of heparin-bonded extracorporeal membrane oxygenation in difficult neurosurgery. Artif Organs 25:627632, 2001

7. Chen YS, Lin JW, Yu HY, Ko WJ, Jerng JS, Chang WT, et al: Cardiopulmonary resuscitation with assisted extracorporeal life-support versus conventional cardiopulmonary resuscitation in adults with in-hospital cardiac arrest: an observational study and propensity analysis. Lancet 372:554-561, 2008

8. Choi R, Andres RH, Steinberg GK, Guzman R: Intraoperative hypothermia during vascular neurosurgical procedures. Neurosurg Focus 26(5):E24, 2009

9. Delgado DH, Rao V, Ross HJ, Verma S, Smedira NG: Mechanical circulatory assistance: state of art. Circulation 106:2046-2050, 2002

10. Dengler J, Cabraja M, Faust K, Picht T, Kombos T, Vajkoczy P: Intraoperative neurophysiological monitoring of extracranial-intracranial bypass procedures. J Neurosurg 119:207-214, 2013

11. Elbourne D, Field D, Mugford M: Extracorporeal membrane oxygenation for severe respiratory failure in newborn infants. Cochrane Database Syst Rev (1):CD001340, 2002

12. Fiser SM, Tribble CG, Kaza AK, Long SM, Zacour RK, Kern JA, et al: When to discontinue extracorporeal membrane oxygenation for postcardiotomy support. Ann Thorac Surg 71:210-214, 2001

13. Friesenecker BE, Peer R, Rieder J, Lirk P, Knotzer H, Hasibeder WR, et al: Craniotomy during ECMO in a severely traumatized patient. Acta Neurochir (Wien) 147:993-996, 2005

14. Fuhrman BP, Hernan LJ, Rotta AT, Heard CM, Rosenkranz ER: Pathophysiology of cardiac extracorporeal membrane oxygenation. Artif Organs 23:966-969, 1999

15. Gibbon JH Jr: Application of a mechanical heart and lung apparatus to cardiac surgery. Minn Med 37:171-185, 1954

16. Gluckman PD, Wyatt JS, Azzopardi D, Ballard R, Edwards $\mathrm{AD}$, Ferriero DM, et al: Selective head cooling with mild systemic hypothermia after neonatal encephalopathy: multicentre randomised trial. Lancet 365:663-670, 2005

17. Hervey-Jumper SL, Annich GM, Yancon AR, Garton HJ, Muraszko KM, Maher CO: Neurological complications of extracorporeal membrane oxygenation in children. J Neurosurg Pediatr 7:338-344, 2011

18. Hill JD, O'Brien TG, Murray JJ, Dontigny L, Bramson ML, Osborn JJ, et al: Prolonged extracorporeal oxygenation for acute post-traumatic respiratory failure (shock-lung syndrome). Use of the Bramson membrane lung. N Engl J Med 286:629-634, 1972

19. Hwang GJ, Sheen SH, Kim HS, Lee HS, Lee TH, Gim GH, et al: Extracorporeal membrane oxygenation for acute life- threatening neurogenic pulmonary edema following rupture of an intracranial aneurysm. J Korean Med Sci 28:962-964, 2013

20. Iijima T, Back T, Hossmann KA: Effect of extracorporeal life support on cerebral blood flow, metabolism and electrophysiology in normothermic cats. Intensive Care Med 21:38-44, 1995

21. Kelly RB, Porter PA, Meier AH, Myers JL, Thomas NJ: Duration of cardiopulmonary resuscitation before extracorporeal rescue: how long is not long enough? ASAIO J 51:665-667, 2005

22. Lidegran MK, Mosskin M, Ringertz HG, Frenckner BP, Lindén VB: Cranial CT for diagnosis of intracranial complications in adult and pediatric patients during ECMO: Clinical benefits in diagnosis and treatment. Acad Radiol 14:62-71, 2007

23. Maeda Y, Nomura S, Kurokawa T, Ishihara H, Harada K, Yoneda $\mathrm{H}$, et al: Cerebrovascular moyamoya disease in a 5 -year-old girl who underwent interruption of the right common carotid artery in the neonatal period. J Neurosurg Pediatr 3:316-319, 2009

24. Massetti M, Tasle M, Le Page O, Deredec R, Babatasi G, Buklas D, et al: Back from irreversibility: extracorporeal life support for prolonged cardiac arrest. Ann Thorac Surg 79:178-184, 2005

25. Mateen FJ, Muralidharan R, Shinohara RT, Parisi JE, Schears GJ, Wijdicks EF: Neurological injury in adults treated with extracorporeal membrane oxygenation. Arch Neurol 68:1543-1549, 2011

26. McManus ML, Kevy SV, Bower LK, Hickey PR: Coagulation factor deficiencies during initiation of extracorporeal membrane oxygenation. J Pediatr 126:900-904, 1995

27. Michaels AJ, Schriener RJ, Kolla S, Awad SS, Rich PB, Reickert C, et al: Extracorporeal life support in pulmonary failure after trauma. J Trauma 46:638-645, 1999

28. Nolan JP, Morley PT, Vanden Hoek TL, Hickey RW, Kloeck WG, Billi J, et al: Therapeutic hypothermia after cardiac arrest: an advisory statement by the advanced life support task force of the International Liaison Committee on Resuscitation. Circulation 108:118-121, 2003

29. Peek GJ, Mugford M, Tiruvoipati R, Wilson A, Allen E, Thalanany MM, et al: Efficacy and economic assessment of conventional ventilatory support versus extracorporeal membrane oxygenation for severe adult respiratory failure (CESAR): a multicentre randomised controlled trial. Lancet 374:1351-1363, 2009

30. Risnes I, Wagner K, Nome T, Sundet K, Jensen J, Hynås IA, et al: Cerebral outcome in adult patients treated with extracorporeal membrane oxygenation. Ann Thorac Surg 81:1401-1406, 2006

31. Sakamoto S, Taniguchi N, Nakajima S, Takahashi A: Extracorporeal life support for cardiogenic shock or cardiac arrest due to acute coronary syndrome. Ann Thorac Surg 94:1-7, 2012

32. Shankaran S, Laptook AR, Ehrenkranz RA, Tyson JE, McDonald SA, Donovan EF, et al: Whole-body hypothermia for neonates with hypoxic-ischemic encephalopathy. N Engl J Med 353:1574-1584, 2005

33. Shin TG, Choi JH, Jo IJ, Sim MS, Song HG, Jeong YK, et al: Extracorporeal cardiopulmonary resuscitation in patients with inhospital cardiac arrest: A comparison with conventional cardiopulmonary resuscitation. Crit Care Med 39:1-7, 2011

34. Short BL: The effect of extracorporeal life support on the brain: a focus on ECMO. Semin Perinatol 29:45-50, 2005

35. Short BL, Walker LK, Bender KS, Traystman RJ: Impairment of cerebral autoregulation during extracorporeal membrane oxygenation in newborn lambs. Pediatr Res 33:289294,1993 
36. Sidebotham D, McGeorge A, McGuinness S, Edwards M, Willcox T, Beca J: Extracorporeal membrane oxygenation for treating severe cardiac and respiratory disease in adults: Part 1-overview of extracorporeal membrane oxygenation. J Cardiothorac Vasc Anesth 23:886-892, 2009

37. Slonim AD, Patel KM, Ruttimann UE, Pollack MM: Cardiopulmonary resuscitation in pediatric intensive care units. Crit Care Med 25:1951-1955, 1997

38. Study G: Mild therapeutic hypothermia to improve the neurologic outcome after cardiac arrest. N Engl J Med 346:549-556, 2002

39. Tasker RC: Extracorporeal cardiopulmonary resuscitation for in-hospital cardiac arrest: lessons from acute neurotoxicity. Pediatr Crit Care Med 10:525-527, 2009

40. Tsuneyoshi H, Rao V: The role of extracorporeal membrane oxygenation (ECMO) therapy in acute heart failure. Int Anesthesiol Clin 50:114-122, 2012

41. Upp JR Jr, Bush PE, Zwischenberger JB: Complications of neonatal extracorporeal membrane oxygenation. Perfusion 9:241-256, 1994

42. Yen TS, Liau CC, Chen YS, Chao A: Extracorporeal membrane oxygenation resuscitation for traumatic brain injury after decompressive craniotomy. Clin Neurol Neurosurg 110:295-297, 2008

43. Zhao H, Steinberg GK, Sapolsky RM: General versus specific actions of mild-moderate hypothermia in attenuating cerebral ischemic damage. J Cereb Blood Flow Metab 27:1879-1894, 2007

\section{Author Contributions}

Conception and design: Steinberg, Choudhri, Shah, Jaffe. Acquisition of data: Choudhri, Shah, Basarab-Tung, Jaffe. Analysis and interpretation of data: all authors. Drafting the article: Choudhri, Shah. Critically revising the article: Steinberg, Choudhri, Shah, Basarab-Tung. Reviewed submitted version of manuscript: all authors. Approved the final version of the manuscript on behalf of all authors: Steinberg.

\section{Correspondence}

Gary K. Steinberg, Department of Neurosurgery, Stanford University School of Medicine, 300 Pasteur Dr., R281, Stanford, CA 94305. email: gsteinberg@stanford.edu. 